\title{
Effect of rope skipping combining calcium pyruvate on fat metabolism of female college students.
}

\author{
Weiguo Gong ${ }^{1}$, Jiange Jiang ${ }^{2 *}$ \\ ${ }^{1}$ Department of Clinical Laboratory, Mengyin County People's Hospital of Shandong Province, PR China \\ ${ }^{2}$ Department of Clinical Laboratory, Dezhou People's Hospital of Shandong Province, PR China
}

\begin{abstract}
Objective: To study the effect of rope skipping combining calcium pyruvate on the fat metabolism of female college students.

Methods: 60 cases of female college students who are over $58 \mathrm{~kg}$ were selected and equally divided into three groups. Group A was given single rope skipping exercise; group B was given single oral calcium pyruvate treatment; and group $\mathrm{C}$ was given rope skipping combining oral calcium pyruvate treatment. Groups $A$ and $C$ were given routine rope skipping for 60 min per $d$. Groups $B$ and $C$ were given calcium pyruvate of $50 \mathrm{mg} / \mathrm{kg}$ for $12 \mathrm{w}$ and twice a day. The physical and psychological indexes of three groups before and after the experiment were observed.

Results: The weight, body fat ratio, Waist-to-Hip Ratio (WHR), body mass, and blood lipid level of three groups after the experiment were significantly lower than before. The differences were statistically significant, with $\mathbf{P}<\mathbf{0 . 0 5}$. Among three groups, the effect of group $\mathrm{C}$ was significantly better than groups $A$ and $B$. The difference was statistically significant, with $P<0.05$.

Conclusion: The combination of rope skipping and calcium pyruvate can effectively speed up the fat metabolism and optimize body shape of female college students, which is worth clinical application and promotion.
\end{abstract}

Keywords: Rope skipping, Calcium pyruvate, Fat metabolism, Effect.

Accepted on June 1, 2017

\section{Introduction}

The constant development of economic level and corresponding changes of life style, we are facing gradually increasing weight, with younger-age trend. As a common metabolic disease in modern society, obesity is mostly caused by unreasonable lifestyle and eating habits. Obesity affects people's health greatly in figures and images as well as diseases including high blood pressure, diabetes, and various cardiovascular diseases [1]. As for female college students, the influence is more in job hunting. Some of them failed to find a satisfied job because of obesity. Exercise is the most effective way to lose weight. Aerobatic exercise, especially, can help reduce fat, lose weight, and change appearance. However, due to the mental and physical challenge, it is hard for many dieters to lost weight in this way.

Pyruvate, a three carbon compound, is the intermediate metabolite of the glycolysis pathway. Pyruvate is the key substrate for energy production by mitochondria [2]. Stanko et al. [3] investigated that pyruvate supplementation could have an effect on the body composition of obese women. Newsholme [4] showed that pyruvate may activate a futile cycle leading to excess energy and fat oxidation.
This paper studies the effect of rope skipping combining calcium pyruvate on the fact metabolism of female college students.

\section{Data and Methods}

\section{General data}

60 cases of female college students who are over $58 \mathrm{~kg}$ were selected and equally divided into three groups. In group A, the age range is 19 to $24 \mathrm{y}$ old, with average age of $20.5 \pm 1.5 \mathrm{y}$ old; and the weight range is 58 to $68 \mathrm{~kg}$, with average weight of $61.5 \pm 1.5 \mathrm{~kg}$. In group $\mathrm{B}$, the age range is 20 to $25 \mathrm{y}$ old, with average age of $20.5 \pm 2.5 \mathrm{y}$ old; and the weight range is 58.6 to $66.4 \mathrm{~kg}$, with average weight of $60.5 \pm 2.5 \mathrm{~kg}$. In group $\mathrm{C}$, the age range is 20 to $23 \mathrm{y}$ old, with average age of $20.5 \pm$ $0.5 \mathrm{y}$ old; and the weight range is 58.8 to $70 \mathrm{~kg}$, with average weight of $62.4 \pm 2 \mathrm{~kg}$. The age and weight of three groups show no significant differences, with $\mathrm{P}>0.05$. Therefore, we can use these data for comparison.

\section{Experiment method}

Group A is given single rope skipping exercise for $60 \mathrm{~min}$ per $\mathrm{d}$ from 17:00 to 18:00. The exercise is divided into 6 groups, 
with $10 \mathrm{~min}$ in a group and $1 \mathrm{~min}$ rest in between. The heart rate is measured during rest time. Two feet and single foot methods are both used in the exercise for consecutive $12 \mathrm{w}$ [5]. Group B is given single oral calcium pyruvate (from Shanghai Helios Technology Co., Ltd) treatment of $50 \mathrm{mg} / \mathrm{kg}$ twice a day for consecutive $12 \mathrm{w}$. During the treatment, any other drugs are forbidden. The calcium pyruvate content is over 99\% [6]. Group $\mathrm{C}$ is given rope skipping combining oral calcium pyruvate treatment. The $60 \mathrm{~min}$ exercise is equally divided into 6 groups of $10 \mathrm{~min}$, with $1 \mathrm{~min}$ rest in between. The heart rate is controlled between 130 and 150 times/min. At the same time, group $\mathrm{C}$ is given oral calcium pyruvate of $50 \mathrm{mg} / \mathrm{kg}$ with the same dosage and duration as group B [7].

\section{Measurements}

Various examines including physical and physiological indexes. Physical indexes such as weight, BMI, body fat, and WHR are given to all objects with body composition analyser (Biospace inbody 720, Korean). Lance clamp crease instrument is used to measure the TSF, SBS, and abdominal skinfold thickness. Blood examine index: Before exercise, $5 \mathrm{ml}$ venous blood of all objects is obtained in the resting state. Automatic biochemical analyser (Roche P800, Germany) is used to measure the physiological indexes including TG, TC, HDL-C, and LDL-C of all objects with oxidizing enzyme method.

\section{Index observation}

Observe the change of physical and physiological indexes of students in three groups before and after experiment.

\section{Statistical method}

All data in this paper is calculated with SPSS 15.0. Weight, BMI, body fat, WHR, TSF, SBS, abdominal skinfold thickness, TG, TC, HDL-C, and LDL-C are measurement data. After ttest, the significant difference among three groups is showed with $\mathrm{P}<0.05$.

\section{Results}

\section{Comparison of weight, BMI, body fat, and WHR before and after experiment}

The weight, BMI, body fat, and WHR of three groups before and after experiment are compared. The result shows the above indexes are reduced that before. The change of group $\mathrm{C}$ is more apparent than groups $\mathrm{A}$ and $\mathrm{B}$. Its weight, BMI, body fat, and WHR are significantly lower than groups $\mathrm{A}$ and $\mathrm{B}$. The difference is statistically significant, with $\mathrm{P}<0.05$, as is shown in Table 1.

Table 1. Comparison of weight, BMI, body fat, and WHR among three groups $(x \pm s)$.

\begin{tabular}{|c|c|c|c|c|c|c|c|c|c|c|c|c|}
\hline \multirow[t]{2}{*}{ Item } & \multicolumn{4}{|c|}{ Group A $(N=20)$} & \multicolumn{4}{|c|}{ Group B $(\mathrm{N}=20)$} & \multicolumn{4}{|c|}{ Group C (N=20) } \\
\hline & $\begin{array}{l}\text { Before } \\
\text { experiment }\end{array}$ & the & $\begin{array}{l}\text { After } \\
\text { experiment }\end{array}$ & the & $\begin{array}{l}\text { Before } \\
\text { experiment }\end{array}$ & the & $\begin{array}{l}\text { After } \\
\text { experiment }\end{array}$ & the & $\begin{array}{l}\text { Before } \\
\text { experiment }\end{array}$ & the & $\begin{array}{l}\text { After } \\
\text { experiment }\end{array}$ & the \\
\hline Weight (kg) & $66.8 \pm 7.2$ & & $60.6 \pm 8.4$ & & $69.5 \pm 8.3$ & & $61.3 \pm 5.7$ & & $70.6 \pm 6.2$ & & $58.7 \pm 7.1$ & \\
\hline BMI & $26.8 \pm 3.4$ & & $24.1 \pm 2.9$ & & $27.4 \pm 3.8$ & & $23.9 \pm 4.2$ & & $25.5 \pm 2.7$ & & $21.6 \pm 3.1$ & \\
\hline Body fat (\%) & $27.5 \pm 6.4$ & & $22.8 \pm 5.9$ & & $27.6 \pm 5.7$ & & $23.1 \pm 4.8$ & & $29.4 \pm 6.6$ & & $21.7 \pm 5.9$ & \\
\hline WHR & $0.86 \pm 0.08$ & & $0.78 \pm 0.06$ & & $0.89 \pm 0.05$ & & $0.75 \pm 0.07$ & & $0.92 \pm 0.07$ & & $0.75 \pm 0.08$ & \\
\hline
\end{tabular}

Note: The difference before and after the experiment is significant, with $\mathrm{P}<0.05$; Compared with groups $\mathrm{A}$ and $\mathrm{B}$, the change of group $\mathrm{C}$ is more apparent. The difference is statistically significant, with $\mathrm{P}<0.05$.

\section{Comparison of TSF, SBS, and abdominal skinfold thickness before and after experiment}

Compare the TSF, SBS, and abdominal skinfold thickness of three groups before and after the experiment. Compared with groups $\mathrm{A}$ and $\mathrm{B}$, the skinfold thickness of group $\mathrm{C}$ increases more apparently. The difference is statistically significant, with $\mathrm{P}<0.05$, as is shown in Table 2 .

Table 2. Comparison of TSF, SBS, and abdominal thickness of three groups before and after experiment $(x \pm s)$.

\begin{tabular}{llll}
\hline Group & TSFmm & SBSmm & $\begin{array}{l}\text { Abdominal } \\
\text { skinfold thickness } \\
(\mathbf{m m})\end{array}$ \\
\hline Group A $(\mathrm{N}=20)$ & $4.18 \pm 1.34$ & $4.57 \pm 2.12$ & $5.32 \pm 1.48$ \\
\hline
\end{tabular}

\begin{tabular}{llll}
\hline Group B $(\mathrm{N}=20)$ & $4.17 \pm 1.26$ & $4.54 \pm 1.87$ & $4.89 \pm 1.54$ \\
\hline Group C (N=20) & $4.52 \pm 1.07$ & $4.49 \pm 2.04$ & $7.28 \pm 1.39$ \\
\hline
\end{tabular}

Note: Compared with groups $\mathrm{A}$ and $\mathrm{B}$, group $\mathrm{C}$ shows significant difference, with $\mathrm{P}<0.05$

\section{Comparison of TG, TC, HDL-C, and LDL-C of three groups before and after experiment}

Compare TG, TC, HDL-C, and LDL-C of three groups before and after the experiment. Compared with groups $\mathrm{A}$ and $\mathrm{C}$, the TG of group $\mathrm{B}$ is significantly different, with $\mathrm{P}<0.05$. Other 
indexes show no significant difference, with $\mathrm{P}>0.05$, as shown in Table 3.

Table 3. Comparison of TG, TC, HDL-C, and LDL-C of three groups before and after experiment $(x \pm s)$.

\begin{tabular}{|c|c|c|c|c|c|}
\hline Group & & TG mg/dL & $\mathrm{TC} \mathrm{mg} / \mathrm{dL}$ & HDL-C mg/dL & LDL-C mg/dL \\
\hline $\begin{array}{l}\text { Group } \\
(\mathrm{N}=20)\end{array}$ & A & $-25.8 \pm 9.6$ & $-38.2 \pm 14.3$ & $2.4 \pm 1.28$ & $-3.8 \pm 1.52$ \\
\hline $\begin{array}{l}\text { Group } \\
(\mathrm{N}=20)\end{array}$ & B & $-32.2 \pm 8.3$ & $-41.6 \pm 13.8$ & $2.1 \pm 1.34$ & $-3.7 \pm 1.61$ \\
\hline $\begin{array}{l}\text { Group } \\
(\mathrm{N}=20)\end{array}$ & C & $-39.9 \pm 9.7$ & $-41.3 \pm 12.7$ & $2.5 \pm 1.13$ & $-4.1 \pm 1.85$ \\
\hline
\end{tabular}

Note: Compared with groups $\mathrm{A}$ and $\mathrm{B}$, TG of group $\mathrm{C}$ is significantly different, with $\mathrm{P}<0.05$.

\section{Discussion}

Obesity refers to the state caused by overweight or excessive body fat. It is not just weight gain, but the excessive accumulation of body fat. Obesity is a pathologic and physiological phenomenon caused by excessive food intake or metabolic problems. Causes of obesity include [8]: genetic factor, environment, material metabolism, endocrine function change, fat cell increasing, lifestyle, eating habits, druginduced obesity, and intestinal tract problem. Simple obesity accounts for $95 \%$ in all. "Middle age obesity" also belongs to simple obesity. Normally, the sugar, fat, and calorie in the daily diet are high. If the intake of fat and sugar is larger than consumption, the excess fat and sugar will lead to fat accumulation. At the same time, excessive intake of alcohol also leads to excess energy and obesity. Obese people are vulnerable to diseases including endocrine dyspraxia, cancer, skin disease, diabetes, high blood pressure, cardiovascular disease, blood lipid metabolic abnormality, gallbladder and pancreas disease, and low respiratory function [9]. Therefore, the influence of obesity is large, especially to female college students, who are in their most beautiful life stage. Obesity will affect their body shape or even job hunting. Some of them lost their job opportunity because of obesity. Therefore, it is good for female college students to control their weight, develop good eating habits and lifestyle, and keep exercise.

Calcium pyruvate is a calcium salt and a dietary supplement, which can speed up fat consumption, help lose weight, enhance endurance, and improve competitive ability. Besides, it can protect heart, strengthen the function of heart muscle, and thus reduce the harm due to heart attack or cardiac ischemia. Calcium pyruvate can effectively reduce body fat, while rope skipping is a systematic exercise. The combination of the above two can help female college students reduce body fat and lose weight quickly.

On the experimental results, it indicated that skipping rope combining calcium pyruvate had a better effect on losing weight than simple exercise group and pure calcium pyruvate group. Meanwhile, Koh-Banerjee et al. suggested that [10] pyruvate supplementation during training may negatively affect some blood lipid levels. Another research showed that pyruvate supplementation decreases TC and LDL concentrations by $4 \%$ and $5 \%$ in hyperlipidemic patients [11]. Several studies have shown that pyruvate enables subjects to prolong the exercise time and increase the amount of glucose extracted during rest and exercise, thereby providing additional energy substrates [12-14].

To sum up, the combination of calcium pyruvate and rope skipping can effectively speed up fat metabolism, help lose weight, and establish a good image, which is worth promotion.

\section{References}

1. Kang J, Zhou Y, He X. Effect of rope skipping combinning calcium pyruvate on fat metabolism of female college students. China Sport Sci Technol 2008; 44: 99-102.

2. Kang YH, Chung SJ, Kang IJ, Park JH, Bunger R. Intramitochondrial pyruvate attenuates hydrogen peroxideinduced apoptosis in bovine pulmonary artery endothelium. Mol Cell Biochem 2001; 216: 37-46.

3. Stanko RT, Tietze DL, Arch JE. Body composition, energy utilization, and nitrogen metabolism with a $4.25-\mathrm{MJ} / \mathrm{d}$ lowenergy diet supplemented with pyruvate. Am J Clin Nutr 1992; 56: 630-635.

4. Newsholme EA. Sounding board. A possible metabolic basis for the control of body weight. N Engl J Med 1980; 302: 400-405.

5. Wang W, Zhao J. Contemporary female college student sport fitness analysis. Contemp Sports Technol 2015; 32: 125-126.

6. Chen A, Sun B, Zhao Yan. The effects of the undergraduates short time exercise ability in the way of variable speed rope skipping. J Nanjing Sport Inst 2016; 15: $54-58$.

7. Liu X, Wang K. Effect of sports on body content of female students in Yangzhou University. Comtemp Sports Technol 2016; 23: 100-101.

8. Bray GA, Kim KK, Wilding PH. Obesity: a chronic relapsing progressive disease process. A position statement of the World Obesity Federation. Obesity Rev 2017.

9. Barbieri M, Desesquelles A, Egidi V. Obesity-related mortality in France, Italy, and the United States: a comparison using multiple cause-of-death analysis. Int J Publ Health 2017; 1-7.

10. Koh-Banerjee PK, Ferreira MP, Greenwood M. Effects of calcium pyruvate supplementation during training on body composition, exercise capacity, and metabolic responses to exercise. Nutrition 2005; 21: 312.

11. Stanko RT, Reynolds HR, Lonchar KD, Arch JE. Plasma lipid concentrations in hyperlipidemic patients consuming a high-fat diet supplemented with pyruvate for $6 \mathrm{wk}$. Am J Clin Nutr 1992; 56: 950-954.

12. Stanko RT, Robertson RJ, Galbreath RW, Reilly JJ, Greenawalt KD. Enhanced leg exercise endurance with a high-carbohydrate diet and dihydroxyacetone and pyruvate. J Appl Physiol 1990; 69: 1651-1656. 
13. Stanko RT, Robertson RJ, Spina RJ. Enhancement of arm exercise endurance capacity with dihydroxyacetone and pyruvate. J Appl Physiol 1990; 68: 119.

14. Stanko RT, Mitrakou A, Greenawalt K, Gerich J. Effect of dihydroxyacetone and pyruvate on plasma glucose concentration and turnover in noninsulin-dependent diabetes mellitus. Clin Physiol Biochem 1990; 8: 283-288.

\section{*Correspondence to}

Jiange Jiang

Department of Clinical Laboratory

Dezhou People's Hospital of Shandong Province

PR China 